\title{
Label-Free Detection of Small Organic Molecules by Molecularly Imprinted Polymer Functionalized Thermocouples: Toward In Vivo Applications
}

Hanne Diliën, ${ }^{\dagger, \#}$ Marloes Peeters, ${ }^{\ddagger}, \#$ Jeroen Royakkers, ${ }^{\dagger}$ Jules Harings, ${ }^{\S}$ Peter Cornelis, $"$ Patrick Wagner, Erik Steen Redeker, ${ }^{\dagger}$ Craig E. Banks, ${ }^{\ddagger}$ Kasper Eersels, ${ }^{\dagger, \|}$ Bart van Grinsven, ${ }^{* \dagger \oplus}{ }^{\dagger}$ and Thomas J. Cleij ${ }^{\dagger \oplus 0}$

\begin{abstract}
${ }^{\dagger}$ Maastricht University, Maastricht Science Programme, P.O. Box 616, 6200 MD Maastricht, The Netherlands
${ }^{\ddagger}$ Manchester Metropolitan University, Faculty of Science and Engineering, School of Science and the Environment, Division of Chemistry and Environmental Science, Chester Street, Manchester M1 5GD, United Kingdom

${ }^{\S}$ Maastricht University, Faculty of Humanities and Sciences, Department of Biobased Materials, Brightlands Chemelot Campus, Urmonderbaan 22, 6167 RD, Geleen, The Netherlands

"KU Leuven, Soft-Matter Physics and Biophysics Section, Department of Physics and Astronomy, Celestijnenlaan 200 D, B-3001 Leuven, Belgium
\end{abstract}

\section{Supporting Information}

ABSTRACT: Molecularly imprinted polymers (MIPs), synthetic polymeric receptors, have been combined successfully with thermal transducers for the detection of small molecules in recent years. However, up until now they have been combined with planar electrodes which limits their use for in vivo applications. In this work, a new biosensor platform is developed by roll-coating MIP particles onto thermocouples, functionalized with polylactic acid (PLLA). As a first proof-ofprinciple, MIPs for the neurotransmitter dopamine were incorporated into PLLA-coated thermocouples. The response of the synthetic receptor layer to an increasing concentration of dopamine in buffer was analyzed using a homemade heattransfer setup. Binding of the template to the MIP layer blocks the heat transport through the thermocouple, leading to less heat loss to the environment and an overall higher temperature in the measuring chamber. The measured temperature increase is correlated to the neurotransmitter concentration, which enables measurement of dopamine levels in the micromolar regime. To demonstrate the general applicability of the proposed biosensor platform, thermocouples were functionalized with similar MIPs for cortisol and serotonin, indicating a similar response and limitof-detection. As the platform does not require planar electrodes, it can easily be integrated in, e.g., a catheter. In this way, it is an excellent fit for the current niche in the market of therapeutics and diagnostics. Moreover, the use of a biocompatible and disposable PLLA-layer further illustrates its potential for in vivo diagnostics.

KEYWORDS: molecularly imprinted polymers (MIPs), dopamine, cortisol, serotonin, dip coating, heat-transfer method (HTM), polylactic (L)-acid (PLLA)
$\mathrm{M}$ olecularly imprinted polymers (MIPs) are synthetic mimics of antibodies that have a predefined selectivity and affinity for their target molecule, similar to that of "natural" antibodies. ${ }^{1,2}$ Additionally, they overcome many issues associated with the use of biological receptors because of their long-term chemical and thermal stability, ${ }^{3,4}$ low-cost synthesis process, ${ }^{5}$ and ability to tailor the MIPs to the application. ${ }^{6}$ There is increasing interest to use these plastic antibodies in several areas, such as affinity separation, ${ }^{7}$ clinical applications, ${ }^{8}$ and biosensing., ${ }^{9,10}$ Traditionally, the main research focus lays in the area of affinity separation, with MIPs being commercially available in the shape of cartridges to extract and purify samples. ${ }^{7,11}$ They have shown excellent selectivity, with the possibility to go down to the level of chiral separations, and are compatible with extraction in complicated matrices. ${ }^{12,13}$ Hoshino et al. have demonstrated that polymer nanoparticles can be used in vivo to bind and remove the bee venom melittin, ${ }^{14}$ with the nanoparticles being cleared from the blood and excreted by the liver. Recently, Haupt et al. presented work with polymeric receptors as an active ingredient in a cosmetic product, where MIPs acts as specific scavengers to trap nonodorous precursors of malodors. ${ }^{15}$

Received: February 20, 2017

Accepted: April 13, 2017

Published: April 13, 2017 
However, the use for MIPs in biosensing platforms remains limited due to the lack of straightforward, fast, and inexpensive readout techniques, ${ }^{16,17}$ and difficulty of direct functionalization of polymer particles onto electrode surfaces. ${ }^{4,18}$ To address the first issue, we will make use of the heat-transfer method (HTM), which ensures fast and low-cost detection compared to conventional chromatography techniques. ${ }^{19,20}$ This versatile readout technique was first reported by van Grinsven et al. in terms of DNA mutation analysis. ${ }^{21}$ In recent years, the platform has been combined with synthetic receptors for the detection of a wide range of targets ranging from small organic molecules ${ }^{22}$ to macromolecular targets such as mammalian cells and bacteria. $^{23,24}$ Although the results of these experiments were promising, the receptor layer was created by pressing the MIP particles into an adhesive layer, covering planar electrodes. ${ }^{18}$ This method is time-consuming, the adhesive layer is not biocompatible, and a planar electrode is hard to incorporate into a platform for in vivo detection. ${ }^{25}$

Therefore, we propose a novel method for directly functionalizing a thermocouple wire that registers the temperature in a liquid compartment in time. The thermocouple was coated with a homogeneous biocompatible and biodegradable polylactic (L)-acid (PLLA) adhesive layer by dip coating. ${ }^{26,27}$ The PLLA layer was then heated above its glass transition temperature giving it rubberlike properties, which allows the MIP particles to sink into the layer after roll coating.

In a first series of experiments, MIPs for dopamine were used to demonstrate the proof-of-principle. Dopamine (DA) was selected because its MIP synthesis has been well-established ${ }^{28}$ and it plays a central role in the efficient functioning of a variety of physiological processes. ${ }^{29}$ Additionally, dopamine is associated with various mental disorders ${ }^{30,31}$ and age-related cognitive decline. ${ }^{32}$ MIP-functionalized thermocouples were exposed to increasing concentrations of dopamine and their response was analyzed using a homemade heat-transfer setup. ${ }^{21}$ In this way, the platform was able to quantify dopamine concentrations in aqueous solutions in the range of $10-60 \mu \mathrm{M}$, which is within the physiologically relevant regime of dopamine in urine. ${ }^{33,34}$

To illustrate that the concept can be readily extended toward the detection of other small organic molecules, thermocouples were functionalized with MIPs for cortisol and serotonin. The corticosteroid, hormone cortisol, plays an important role in the body's response to stress, ${ }^{35}$ while the serotoninergic system steers numerous behavioral functions including emotion, sleep, and appetite and is involved in numerous disorders including depression, anorexia, and migraine. ${ }^{36}$ The results of these experiments demonstrate that the sensor responds to these targets when functionalized with the corresponding MIP in a manner similar to that of dopamine.

The proposed functionalization procedure, combined with the low-cost nature of both the receptor layer and the readout methodology, illustrates the potential of the biosensor platform in terms of the current niche in the market of therapeutics and diagnostics for the rapid and inexpensive quantification of compounds in vivo. As the method allows one to directly immobilize the receptor particles onto the thermocouple wire it can be readily extended toward, e.g., coating a catheter for in vivo detection of small organic molecules in bodily fluids. Additionally, both the adhesive layer and the MIP particles are biocompatible and disposable, which are important characteristics in terms of in vivo diagnostic applications.

\section{EXPERIMENTAL METHODS}

Reagents. The chemicals for the MIP synthesis, ethylene glycol dimethacrylate (EGDMA), methacrylic acid (MAA), dopamine hydrochloride salt (purity 99\%), and the initiator 4,4'-azobis(4cyanovaleric acid), were purchased from Acros (Loughborough, United Kingdom). Hydrocortisone (purity 98\%) and azobis(isobutyronitrile) were purchased from Acros (The Netherlands). Stabilizers in the monomers MAA and EGDMA were removed by running the solutions over an alumina packed column. PLLA 1010, used as the adhesive layer, was ordered from Corbion Purac (Amsterdam, The Netherlands). Thermocouples type $\mathrm{K}(0.5 \mathrm{~mm} \times$ $30 \mathrm{~mm}$ ) were obtained from TC Direct (Maarssen, The Netherlands).

Functionalization Approach. Details of the dopamine and serotonin MIP synthesis protocols are described in refs 22 and 37. After removal of the template from the MIPs, the bulk of the polymer was ground and sieved to obtain microparticles with sizes smaller than $10 \mu \mathrm{m}$. A nonimprinted reference (NIP) was synthesized in the same manner, but without the presence of dopamine. Cortisol MIPs were produced by dissolving hydrocortisone $(0.5 \mathrm{mmol})$, MAA $(5 \mathrm{mmol})$, EGDMA (44.8 mmol), and azobisosobutyronitrile $(0.2 \mathrm{mmol})$ in 7 $\mathrm{mL}$ chloroform. The mixture was degassed with nitrogen for $5 \mathrm{~min}$ and then placed in a rotating UV oven at $4{ }^{\circ} \mathrm{C}$ for $42 \mathrm{~h}$. The resulting polymer block was ground and sieved to obtain particles $<50 \mu \mathrm{m}$. To remove the template, a Soxhlet extraction was employed using the following solvents: methanol $(24 \mathrm{~h})$, followed by a $1: 1$ ratio of acetonitrile to acetic acid $(48 \mathrm{~h})$, and methanol again $(24 \mathrm{~h})$. This protocol was adapted from a protocol developed by Baggiani et al. ${ }^{11}$ The same protocol was followed to synthesize the NIP, but without the addition of the hydrocortisone. These MIP and NIP powders were subsequently functionalized onto thermocouples coated with PLLA.

To obtain a PLLA sheet around the thermocouple, PLLA (200 mg/ $\mathrm{mL}$ ) was first dissolved into chloroform by heating it under reflux for 2 h. Subsequently, the thermocouples were dipped into the PLLA solution for $10 \mathrm{~s}$ and withdrawn at a rate of $0.39 \mathrm{~cm} / \mathrm{min}$. The PLLAcoated thermocouples were heated above the glass transition temperature of the polymer $\left(75^{\circ} \mathrm{C}\right)$, allowed to incorporate the MIP particles by manual roll coating at $75{ }^{\circ} \mathrm{C}$. After rapid cooling of the layer for $5 \mathrm{~min}$, the PLLA returned to its original crystalline state, trapping the MIP particles inside the layer. Functionalized thermocouples were rinsed with isopropanol to remove any unbound particles from the adhesive layer.

Characterization of MIP Coating Properties. Optical images were acquired with an Olympus BX 35 Microscope (Zoeterwoude, The Netherlands) to determine the thickness of the polymer coating and the surface coverage of the MIPs. Surface coverage was determined by performing SPIP (software available at http://www. imagemet.com). The MIP powders are white and have a different appearance than the transparent PLLA undercoat. The contrast of the optical images is adjusted to create pixels of a size of $1 \mu \mathrm{m}$ in order to digitally distinguish between the MIP and the underlying coating. The difference between pixelated (MIP) and nonpixelated (noncoated area) is used to determine the proportion of the surface covered with microparticles. To compare the wires, for each MIP or NIP the same region on the $2 \mathrm{D}$ optical image was sampled. An example of this process is provided in the Supporting Information.

Heat-Transfer Measurements. The homemade heat-transfer setup is described in detail in previous work. ${ }^{21}$ The heat-transfer setup was connected to a Perspex flow cell with an inner volume of $110 \mu \mathrm{L}$ and sealed off with an O-ring. The copper block of the setup serves as a heat sink or a heat provider and its temperature, $T_{1}$, is actively steered by a proportional-integral-derivative (PID) controller coupled to a power resistor. In all measurements, this temperature was kept constant at $37.00{ }^{\circ} \mathrm{C}$ to mimic body temperature. The thermocouple functionalized with MIP particles measures the temperature inside the flow cell, which is defined as $T_{2}$ (Figure 1).

Prior to measuring, the flow cell was filled with phosphate buffered saline (PBS) solutions and the signal is left to stabilize for $45 \mathrm{~min}$ after the start of the measurement. The concentration of target is increased subsequently by introducing target solutions in PBS with different 


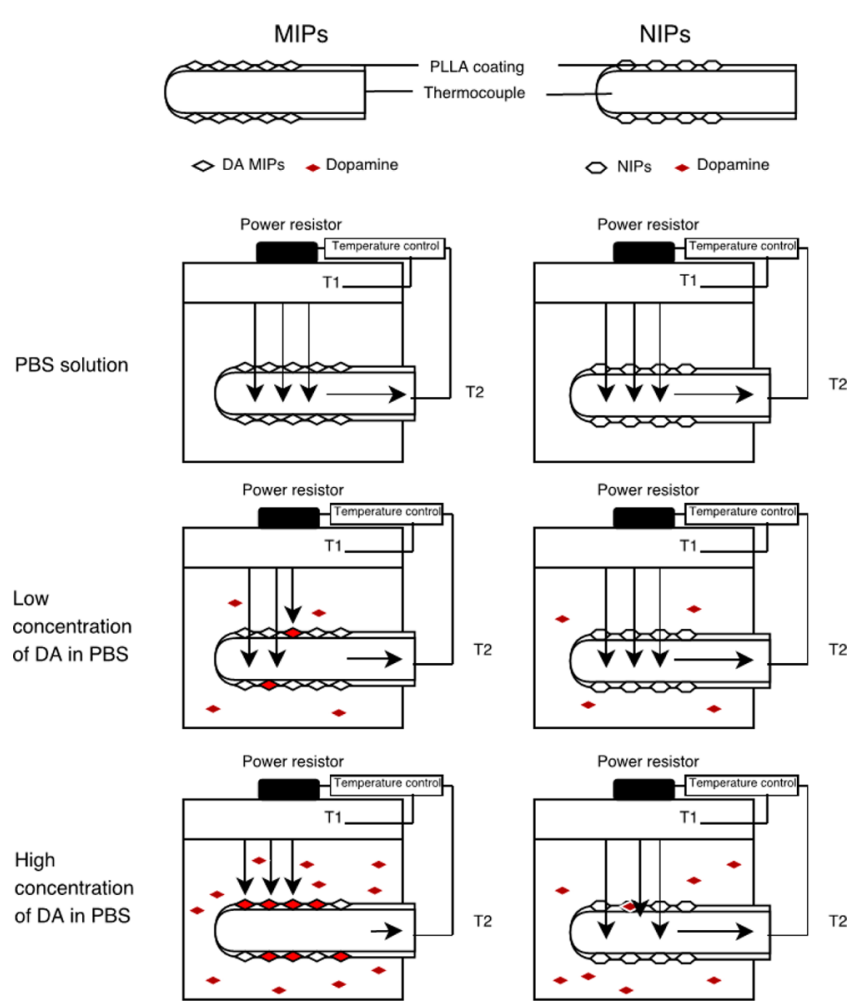

Figure 1. Schematic representation of the heat flow through the MIPand NIP-coated thermocouples, represented by the position and size of the arrows. It is observed that binding of dopamine (red dots) decreases the transfer of heat from the liquid inside the flow cell to the thermocouple. This will result in an increase in $T_{2}$ as less heat will be lost to the environment via the thermocouple.

concentrations $(0,0.5,1,2,5,10,15,20,25,50 \mu \mathrm{M})$ at a constant rate of $0.25 \mathrm{~mL} \mathrm{~min}^{-1}$, using an automated syringe pump. The signal is allowed to stabilize for $30 \mathrm{~min}$ between each addition. Throughout the measurement, $T_{1}$ and $T_{2}$ were recorded and plotted vs the concentration to obtain a dose-response curve. The temperature of $T_{1}$ is actively steered and no changes are expected here, while $T_{2}$ is monitored and will be affected by the concentration of dopamine bound to the MIP layer.

\section{RESULTS}

Surface Analysis of the Coating. An optical analysis of the coating procedure is summarized in Figure 2. Images were obtained for an uncoated (left), PLLA-coated (middle), and MIP/NIP-functionalized thermocouple. These images were used to determine the surface coverage by SPIP analysis
(Supporting Information). Surface coverages of $48 \pm 1 \%$ and $49 \pm 1 \%$ were obtained for MIP and NIP, respectively.

Quantitative Dopamine Detection. All measurements were performed according to the scheme described in the Experimental Methods of the manuscript. The results for a dopamine MIP-coated thermocouple and its reference are show in Figure 3.

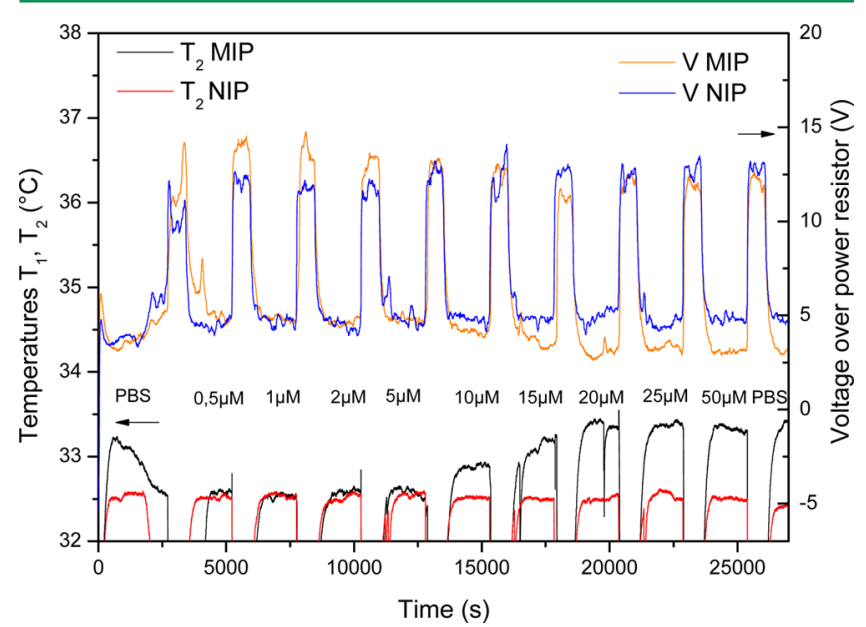

Figure 3. Blue and orange lines represent the voltage over the power resistor for the dopamine MIP- and NIP-coated thermocouples, respectively. In addition, the red and black lines show the temperature $\mathrm{T}_{2}$ as measured by the thermocouple functionalized with MIP (black) and with NIP (red). The results were measured in time after exposure of the thermocouples to dopamine solutions in PBS with increasing concentrations of dopamine $(0-50 \mu \mathrm{M})$ and clearly indicate that $\mathrm{T}_{2}$ increases and $\mathrm{V}$ decreases for the MIP at high dopamine concentrations, while both signals remain unaffected when measuring with a nonimprinted reference.

It can be seen that the temperature inside the flow cell, $T_{2}$, registered by the thermocouple, drops immediately after each addition step (black and red curves). This can be explained by the fact that cool liquid is injected into the flow cell. The signal restores itself due to the PID-controlled steering of $T_{1}$. Therefore, the voltage over the power resistor (blue and orange curves), needed to keep the temperature of the copper block constant, increases after each step. Both the temperature and the voltage were allowed to stabilize after each addition step by stopping flow for $30 \mathrm{~min}$. The resulting voltage signal over the power resistor stays more or less constant upon stabilization over the entire concentration range for the measurements with a NIP-coated thermocouple. However, the measurement with the MIP-coated thermocouple indicates

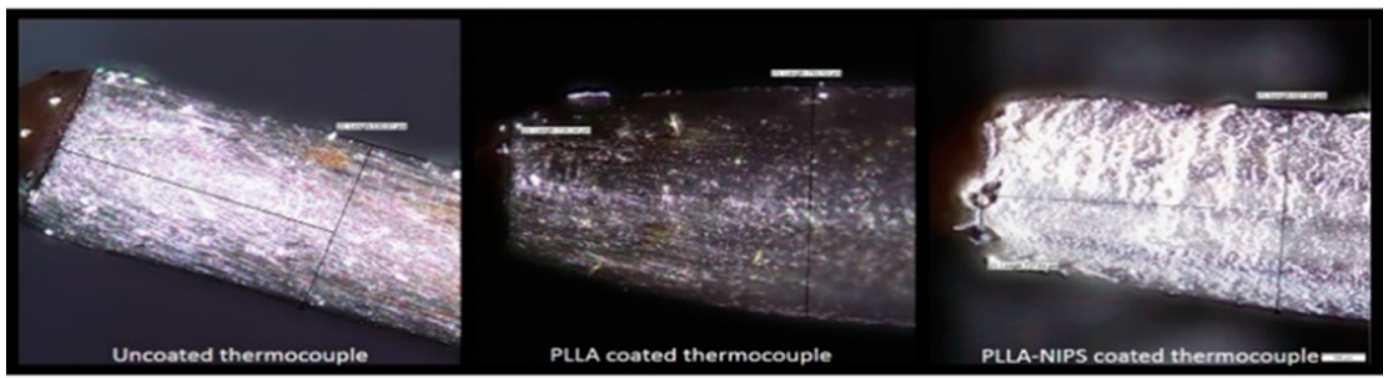

Figure 2. Thermocouples ( $2 \mathrm{~mm}$ from the tip) imaged by optical microscopy before and after PLLA coating and after attachment of the polymer powder. 
that the voltage over the power resistor starts decreasing from 5 to $2.5 \mathrm{~V}$ at increasing concentrations above $10 \mu \mathrm{M}$.

More distinct differences between the MIP and NIP were observed in the temperature $\mathrm{T}_{2}$; both thermocouples stabilized at a temperature of $\pm 32.5{ }^{\circ} \mathrm{C}$, after addition of $10 \mu \mathrm{M}$ dopamine in PBS the temperature increased to $\pm 32.9{ }^{\circ} \mathrm{C}$ for the MIP, while no significant effect was found in the experiment with the NIP-coated electrode. This effect becomes more pronounced as the concentration inside the flow cell increases and levels off at concentration above $25 \mu \mathrm{M}$.

To demonstrate that the observed effects are reproducible, measurements were performed with an additional three samples that were functionalized with MIP particles. The results of these independent measurements are provided in Figure 4 and show a similar pattern for all MIPs under study.

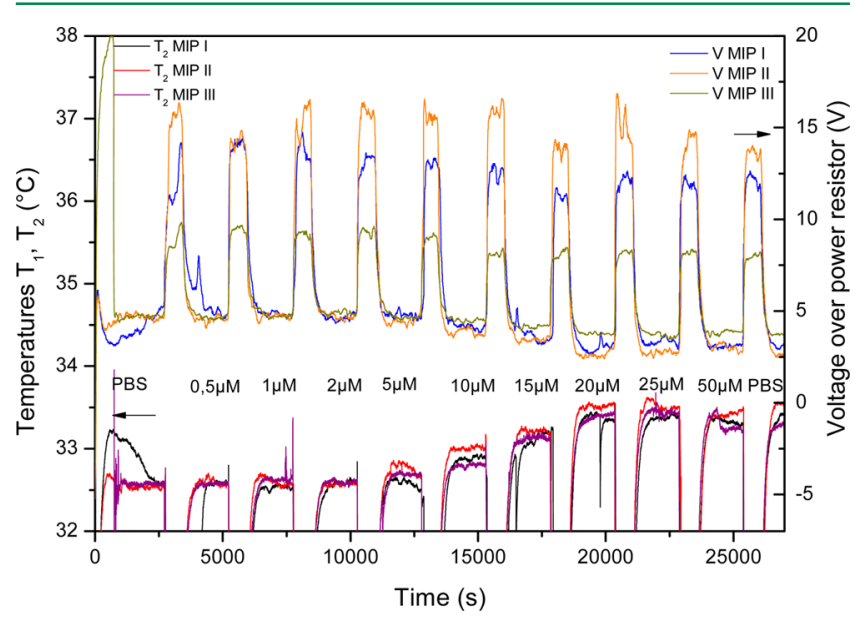

Figure 4. Reproducibility experiment: the blue, orange, and green lines demonstrate the voltage over the power resistor for three different thermocouples that were functionalized with dopamine MIP particles. The functionalized thermocouples were exposed to solutions of PBS with increasing concentrations of dopamine $(0-50 \mu \mathrm{M})$. The red, black, and purple lines show the temperature $\mathrm{T}_{2}$ as measured by the MIP-functionalized thermocouples, which was nearly identical for the three samples.

Dose-Response Curve. The results summarized in the previous chapter were used to determine the effect size and construct a dose-response curve. The effect size was calculated according to eq 1 . In this equation, $\mathrm{T}_{2}(c=x)$ represents the temperature when a certain concentration of dopamine $(c=x)$ was added. This value was taken when the temperature stabilized and reached a new plateau level. $\mathrm{T}_{2} \quad(c=0)$ corresponds to the baseline and is the temperature that is measured when no target is present.

$$
\text { effect size }(\%)=\frac{\mathrm{T}_{2}(c=x)}{\mathrm{T}_{2}(c=0)} \times 100
$$

The effect sizes were determined for the MIP and NIP and plotted as a function of the target concentration (Figure 5) to obtain dose-response curves. The data could be fitted with a standard sigmoidal dose-response fit $\left(R^{2}=0.99\right.$ for MIP and NIP). The dose-response curve reveals a concentrationdependent increase between 10 and $100 \mu \mathrm{M}$ after which the signal saturates.

General Applicability of the Setup. The results presented in the previous sections illustrate the potential of the platform for detecting dopamine in aqueous media. To

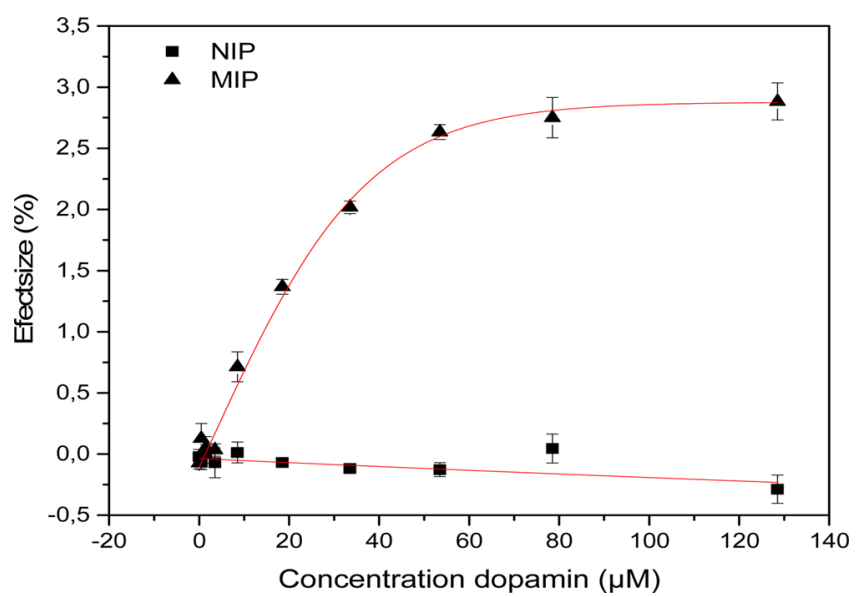

Figure 5. Cumulative dopamine concentration $(\mu \mathrm{M})$ is plotted vs the effect size to construct the corresponding dose-response curve. The effect size is determined as the temperature at a certain dopamine concentration in PBS divided by the temperature in PBS multiplied by 100. Error bars were calculated by taking the standard deviation of three independent MIP and NIP measurements.

determine whether or not the concept could be extended toward other small organic residues, MIPs were synthesized for the corticoid steroid cortisol and the neurotransmitter serotonin as described in the Experimental Methods. These particles were incorporated into PLLA-coated thermocouples using an analogous procedure as described for the dopamine MIPs. MIP- and NIP-coated thermocouples were analyzed using HTM in a manner similar to the experiments described above for the dopamine MIP. The resulting time-dependent temperature and voltage profiles and dose-response curves for both experiments are summarized in Figure 6. These experiments demonstrate that similar values for the detection limit and dynamic range were found for cortisol and serotonin.

\section{DISCUSSION}

Optical analysis of the functionalized thermocouples reveals that the MIP particles attach firmly to the adhesive PLLA layer. In this way, the functionalization process has proven to be an elegant method to immobilize MIP particles directly onto a sensing element. The surface coverage was determined by SPIP analysis and reveals that the method is very reproducible with average surface coverages of $48 \pm 1 \%$ and $49 \pm 1 \%$ for NIP and MIP, respectively. Each sample had a similar surface coverage and particle distribution, which is a precondition to perform differential measurements and compare the results obtained by the thermal measurements. In addition, the achieved surface coverage appears to be a lot better in comparison to the surface coverage of $30 \pm 1 \%$ that was achieved previously by stamping polymer particles into a poly[2]methoxy-5- $\left(3^{\prime}, 7^{\prime}\right.$-dimethyloctyloxy)-1,4-phenylenevinylene (MDMO-PPV) layer on planar electrodes. $^{22}$ The PLLA adhesive layer has the additional benefit of being low-cost, biocompatible, and biodegradable. However, since the total surface area of the thermocouple is about a factor of 8 lower $\left(0.126 \mathrm{~cm}^{2}\right.$ versus $1 \mathrm{~cm}^{2}$ for the planar electrode), the total amount of MIP particles present on the thermocouple will be a factor of 5 lower in comparison to the planar electrodes used previously.

The concentration-dependent increase in $\mathrm{T}_{2}$ observed during the heat-transfer analysis can be explained by the scheme in Figure 1 . In the absence of the target, a constant amount of heat 

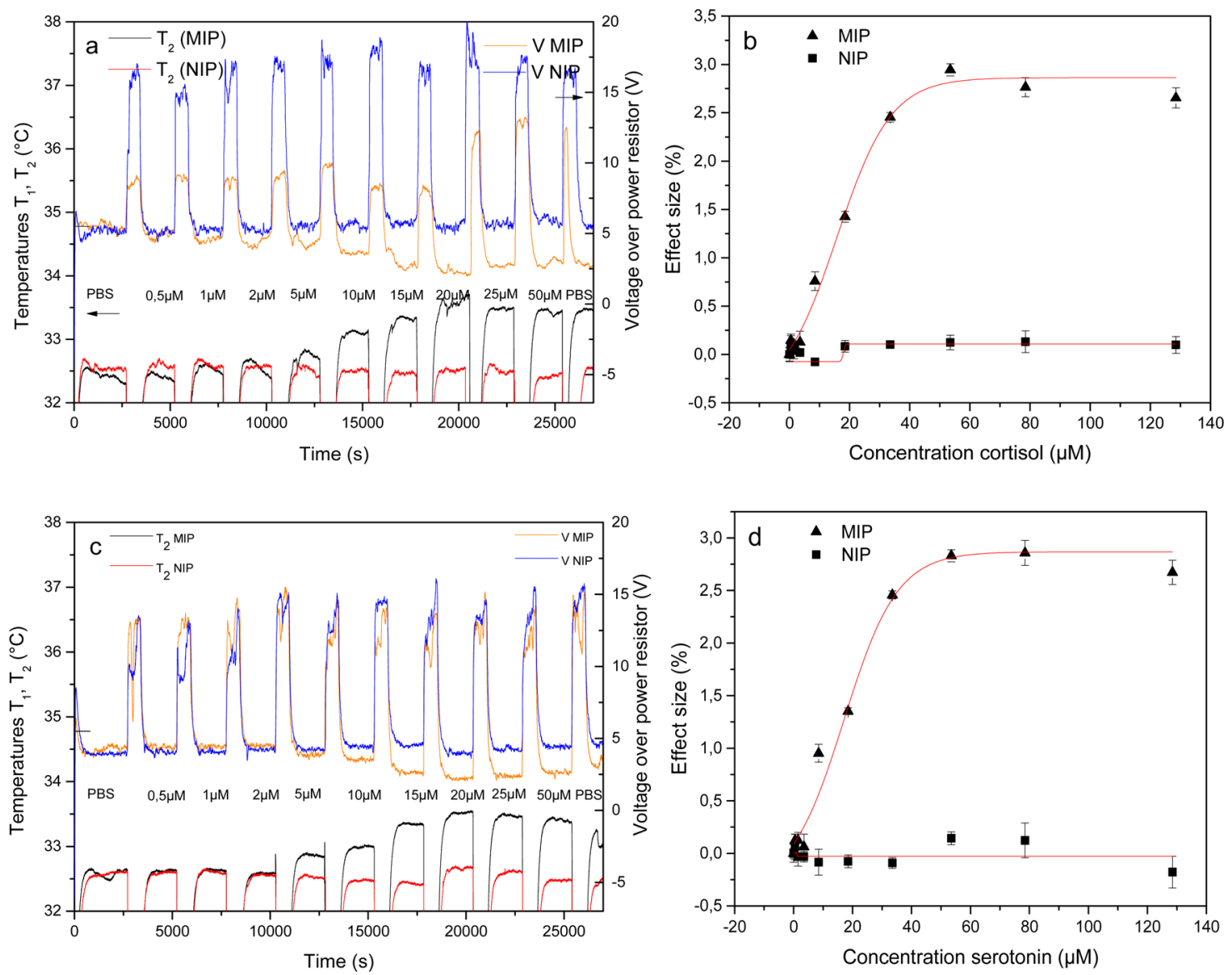

Figure 6. Rebinding experiment using cortisol and serotonin MIPs. Time-dependent temperature and voltage profiles are shown in response to an increasing concentration of cortisol and serotonin in (a) and (c), respectively. Corresponding dose-response curves are also shown in (b) and (d); the error bars on the data represent the standard error on the average over three measurements on three individual thermocouples, functionalized with the same MIP. The results demonstrate a similar behavior to that observed in experiments using dopamine MIPs.

is transported from the liquid to the thermocouple through the MIP particles and the PLLA layer. However, according to the "pore-blocking" model, binding of small molecules into the nanocavities of the MIP will block the heat flow through the MIP layer. ${ }^{22}$ In this case, less heat will be transported into the thermocouple which, in turn, transports the heat away from the flow cell. The decrease in heat loss to the environment would explain why $\mathrm{T}_{2}$ would stabilize at a higher value at equilibrium. Although it has to be noted that this particular model described the effect of MIPs onto electrodes and has not been applied to MIP-functionalized thermocouples before, the voltage drop over the power resistor at high dopamine concentration provides further evidence for this theory, as it would require less energy to keep the heat-sink at a fixed temperature when there is less heat loss to the environment.

The observed effect appears to be concentration-dependent with a limit-of-detection of $\pm 8 \mu \mathrm{M}$ and a linear range from 8 to $60 \mu \mathrm{M}$. Although the limit-of-detection (LoD) is roughly an order of magnitude lower in comparison to the LoD of a similar platform using screen-printed MIP electrodes, ${ }^{36}$ the linear range of the sensor corresponds fairly well with the physiologically relevant concentration range of dopamine in serum and urine, that lies between 1 and $25 \mu \mathrm{M} .^{31}$ The limited sensitivity and narrow dynamic range of the sensor can be partially explained by the smaller surface area of the thermocouple in comparison to the planar electrodes. In addition, the stamping and screen-printing strategies used in previous research ${ }^{22,37}$ were the result of years of optimization. The current technique can be improved by increasing the available surface area (thicker thermocouples, increased coating length, etc.) and optimizing the immobilization strategy (optimizing layer thickness, surface coverage, particle distribution, etc.) to boost the sensitivity of the device toward the nanomolar regime.

The reproducibility and general applicability of the sensor were also demonstrated in this work. NIP-coated thermocouples did not seem to react significantly to each of the target molecules even in very high concentrations while MIPs for different targets displayed the same concentration-dependent behavior with similar LoDs and DRs. Moreover, the maximum increase in temperature of $\pm 1{ }^{\circ} \mathrm{C}$ corresponds well to concentration-dependent effects on thermal transport, associated with the binding of both large macromolecular entities, such as cells, to surface-imprinted polyurethane layers ${ }^{23,24}$ and small organic molecules to MIP particles immobilized onto planar electrodes. ${ }^{2,37}$

\section{CONCLUSION}

The work in this article describes an elegant procedure for immobilizing a synthetic receptor layer, in this case composed of MIPs imprinted with dopamine, cortisol, and serotonin, directly on a thermocouple wire. Optical image analysis revealed that the MIPs firmly attach to the PLLA-coated thermocouple in a very reproducible manner. The $\mathrm{LoD}$ of the 
sensor of $10 \mu \mathrm{M}$ and dynamic range of $10-80 \mu \mathrm{M}$ would allow the end-user to faithfully measure the concentration of dopamine in physiological values in urine and serum. Future research should be aimed at improving the immobilization process in order to further improve the sensitivity and dynamic range of the current platform.

The major advantage of the sensor lies in its unique, userfriendly design. MIP particles are incorporated directly onto the sensing element, thereby overcoming the need for planar electrodes or chips. In addition, the platform is biocompatible and the PLLA layer is degradable making the sensing element disposable. In this way, the interesting combination of robust synthetic receptors and a low-cost thermal readout platform is translated into a device that suits the current market needs. The observations summarized in this paper could be extrapolated to, e.g., catheters or dipstick devices that would allow for in vivo or point-of-care detection of small organic residues.

\section{ASSOCIATED CONTENT}

\section{S Supporting Information}

The Supporting Information is available free of charge on the ACS Publications website at DOI: 10.1021/acssensors.7b00104.

Demonstration of SPIP software to determine surface coverage (PDF)

\section{AUTHOR INFORMATION}

\section{Corresponding Author}

*E-mail: kasper.eersels@maastrichtuniversity.nl. Tel.: 0031/(0) 6.39.60.22.89.

\section{ORCID}

Erik Steen Redeker: 0000-0002-5658-5066

Craig E. Banks: 0000-0002-0756-9764

Bart van Grinsven: 0000-0002-6939-0866

Thomas J. Cleij: 0000-0003-0172-9330

\section{Author Contributions}

${ }^{\#}$ H.D. and M.P. contributed equally. The thermal wave transport device was designed by B.v.G. and T.J.C. TWTA measurements, data processing, and interpretation were performed by B.v.G. and K.E. All MIPs were synthesized by M.P and H.D. and input on the synthesis and template removal protocol was provided by J.H., C.B., and T.J.C. Software design and programming were done by P.C. and P.W. Input on possible medical/biotechnological applications and experimental desing were provided by E.S.R., P.W., and T.J.C. The manuscript was jointly written by H.D., M.P., and K.E. All authors have given approval to the final version of the manuscript.

\section{Notes}

The authors declare no competing financial interest.

\section{ACKNOWLEDGMENTS}

This research has been supported with a financial contribution of the Province of Limburg and the Edmond Hustinx stichting. Technical assistance for the polymer synthesis was provided by J. Lowdon, D. Belami, and S. Khatun.

\section{REFERENCES}

(1) Wullf, G. Enzyme-like Catalysis by Molecularly Imprinted Polymers. Chem. Rev. 2002, 102, 1-28.
(2) Sellergren, B.; Allender, C. J. Molecularly Imprinted Polymers: A Bridge to Advanced Drug Delivery. Adv. Drug Delivery Rev. 2005, 57, 1733-1741.

(3) Whitcombe, M. J.; Kirsch, N.; Nicholls, I. A. Molecular Imprinting Science and Technology: A Survey of the Literature for the Years 2004-2011. J. Mol. Recognit. 2014, 27, 297-401.

(4) Chianella, I.; Guerreiro, A.; Moczko, E.; Caygill, J. S.; Piletska, E. V.; De Vargas Sansalvador, I. M. P.; Whitcombe, M. J.; Piletsky, S. A. Direct Replacement of Antibodies with Molecularly Imprinted Polymer Nanoparticles in ELISA-Development of a Novel Assay for Vancomycin. Anal. Chem. 2013, 85, 8462-8468.

(5) Haupt, K.; Mosbach, K. Molecularly Imprinted Polymers and Their Use in Biomimetic Sensors. Chem. Rev. 2000, 100, 2495-2504.

(6) Ye, L.; Haupt, K. Molecularly Imprinted Polymers as Antibody and Receptor mimics for Assays, Sensors and Drug Discovery. Anal. Bioanal. Chem. 2004, 378, 1887-1897.

(7) Huang, B. Y.; Chen, Y. C.; Wang, G. R.; Liu, C. Y. Preparation and Evaluation of a Monolithic Molecularly Imprinted Polymer for the Chiral Separation of Neurotransmitters and Their Analogues by Capillary Electrochromatography. J. Chrom. A 2011, 1218, 849-855.

(8) Peeters, M.; Troost, F. J.; Mingels, R. H. G.; Welsch, T.; van Grinsven, B.; Vranken, T.; Ingebrandt, S.; Thoelen, R.; Cleij, T. J.; Wagner, P. Impedimetric Detection of Histamine in Bowel Fluids Using Synthetic Receptors with $\mathrm{pH}$-Optimized Binding Characteristics. Anal. Chem. 2013, 85, 1475-1483.

(9) Yano, K.; Karube, I. Molecularly Imprinted Polymers for Biosensor Applications. TrAC, Trends Anal. Chem. 1999, 18, 199-204.

(10) Vlatakis, G.; Andersson, L. I.; Muller, R.; Mosbach, K. Drug Assay Using Antibody Mimics Made by Molecular Imprinting. Nature 1993, 361, 645-647.

(11) Baggiani, C.; Giraudi, G.; Trotta, F.; Giovannoli, C.; Vanni, A. Chromatographic Characterization of a molecular Imprinted Polymer Binding Cortisol. Talanta 2000, 51, 71-75.

(12) Chen, J.; Liang, R. P.; Wang, X. N.; Qiu, J. D. A Norepinephrine Coated Magnetic Molecularly Imprinted Polymer for Simultaneous Multiple Chiral Recognition. J. Chrom. A 2015, 1409, 268-276.

(13) Arnold, F. H.; Striegler, S.; Sundaresan, V. Chiral Ligand Exchange Adsorbents for Amines and Underivatized Amino Acids: 'Bait-and-Switch' Molecular Imprinting: Molecular and Ionic Recognition with Imprinted Polymers. ACS Symp. Ser. 1998, 703, 109-118.

(14) Hoshino, Y.; Koide, H.; Urakami, T.; Kanazawa, H.; Kodama, T.; Oku, N.; Shea, K. J. Recognition, Neutralization, and Clearance of Target Peptides in the Bloodstream of Living Mice by Molecularly Imprinted Polymer Nanoparticles: a Plastic Antibody. J. Am. Chem. Soc. 2010, 132, 6644-6645.

(15) Nestora, S.; Merlier, F.; Beyazit, S.; Prost, E.; Duma, L.; Baril, B.; Greaves, A.; Haupt, K.; Tse Sum Bui, B. Plastic Antibodies for Cosmetics: Molecularly Imprinted Polymers Scavenge Precursors of Malodors. Angew. Chem., Int. Ed. 2016, 55, 6252-6256.

(16) Eppler, S.; Stegmaier, M.; Meier, F.; Mizaikoff, B. A Novel Extraction Device for Efficient Clean-Up of Molecularly Imprinted Polymers. Anal. Methods 2012, 4, 2296-2299.

(17) Murase, N.; Taniguchi, S. I.; Takano, E.; Kitayama, Y.; Takeuchi, T. Fluorescence Reporting of Binding Interactions of Target Molecules with Core-Shell-Type Cortisol-Imprinted Polymer Particles using Environmentally Responsible Fluorescent-Labeled Cortisol. Macromol. Chem. Phys. 2015, 216, 1396-1404.

(18) Thoelen, R.; Vansweevelt, R.; Duchateau, J.; Horemans, F.; D'Haen, J.; Lutsen, L.; Vanderzande, D.; Ameloot, M.; vande Ven, M.; Cleij, T. J. A MIP-Based Impedimetric Sensor for the Detection of Low-MW Molecules. Biosens. Bioelectron. 2008, 23, 913-918.

(19) Wackers, G.; Cornelis, P.; Kellens, E.; Thoelen, R.; De Ceuninck, W.; Losada-Pérez, P.; van Grinsven, B.; Peeters, M.; Wagner, P. Array Formatting of the Heat-Transfer Method (HTM) for the Detection of Small Organic Molecules by Molecularly Imprinted Polymers. Sensors 2014, 14, 11016-11030.

(20) van Grinsven, B.; Eersels, K.; Peeters, M.; Losada-Pérez, P.; Vandenryt, T.; Cleij, T. J.; Wagner, P. The Heat-Transfer Method: A Versatile Low-Cost, Label-Free, Fast and User-Friendly Readout 
Platform for Biosensor Applications. ACS Appl. Mater. Interfaces 2014, 6, 13309-13318.

(21) van Grinsven, B.; Vanden Bon, N.; Strauven, H.; Grieten, L.; Murib, M. S.; Jimenez Monroy, K. L.; Janssens, S. D.; Haenen, K.; Schöning, M. J.; Vermeeren, V.; Ameloot, M.; Michiels, L.; Thoelen, R.; De Ceuninck, W.; Wagner, P. Heat-Transfer Resistance at SolidLiquid Interfaces: A Tool for the Detection of Single-Nucleotide Polymorphisms in DNA. ACS Nano 2012, 6, 2712-2721.

(22) Peeters, M.; Csipai, P.; Geerets, B.; Weustenraed, A.; van Grinsven, B.; Thoelen, R.; Gruber, J.; De Ceuninck, W.; Cleij, T. J.; Troost, F. J.; Wagner, P. Heat-Transfer-Based Detection of L-Nicotine, Histamine, and Serotonin Using Molecularly Imprinted Polymers as Biomimetic Receptors. Anal. Bioanal. Chem. 2013, 405, 6453-6460.

(23) Eersels, K.; van Grinsven, B.; Khorshid, M.; Somers, V.; Püttmann, C.; Stein, C.; Barth, S.; Diliën, H.; Bos, G. M. J.; Germeraad, W. T. V.; Cleij, T. J.; Thoelen, R.; De Ceuninck, W.; Wagner, P. Heat-Transfer-Method-Based Cell Culture Quality Assay through Cell Detection by Surface Imprinted Polymers. Langmuir 2015, 31, 2043-2050.

(24) Eersels, K.; van Grinsven, B.; Ethirajan, A.; Timmermans, S.; Jiménez Monroy, K. L.; Bogier, J. F. J.; Punniyakoti, S.; Vandenryt, T.; Hendriks, J. J. A.; Cleij, T. J.; Daemen, M. J. A. P.; Somers, V.; De Ceuninck, W.; Wagner, P. Selective identification of macrophages and cancer cells based on thermal transport through surface-imprinted polymer layers. ACS Appl. Mater. Interfaces 2013, 5, 7258-7267.

(25) Vandenbergh, J.; Wouters, J.; Adriaensens, P. J.; Mens, R.; Cleij, T. J.; Lutsen, L.; Vanderzande, D. Exploring the Dithiocarbamate Precursor Route: Observation of a Base Induced Regioregularity Excess in Poly $[(2$-methoxy-5-(3',7'-dimethyloctyloxy $))-1,4$-phenylenevinylene] (MDMO-PPV). Macromolecules 2009, 42, 3661-3668.

(26) Athanasiou, K. A.; Niederauer, G. G.; Agrawal, C. M. Sterilization, Toxicity, Biocompatibility and Clinical Applications of Polylactic Acid/Polyglycolic Acid Copolymers. Biomaterials 1996, 17, 93-102.

(27) Anderson, J. M.; Shive, M. S. Biodegradation and Biocompatibility of PLA and PLGA Microspheres. Adv. Drug Delivery Rev. 2012, $64,72-82$.

(28) Lulinski, P.; Maciejewska, D.; Bamburowicz-Klimkowska, M.; Szutowski, M. Dopamine-imprinted polymers: template-monomer interactions, analysis of template removal and application to solid phase extraction. Molecules 2007, 12, 2434-2449.

(29) Bäckman, L.; Lindenberger, U.; Li, S. C.; Nyberg, L. Linking Cognitive Aging to Alterations in Dopamine Neurotransmitter Functioning: Recent Data and Future Avenues. Neurosci. Biobehav. Rev. 2010, 34, 670-677.

(30) Moghaddam, B. Stress Activation of Glutamate Neurotransmission in the Prefrontal Cortex: Implications for DopamineAssociated Psychiatric Disorders. Biol. Psychiatry 2002, 51, 775-787.

(31) Brown, A.; Gershon, S. Dopamine and Depression. J. Neural Transmission 1993, 91, 75-109.

(32) Arnsten, A.; Cai, J.; Steere, J.; Goldman-Rakic, P. Dopamine D2 Receptor Mechanisms Cotribute to Age-Related Cognitive Decline: the Effects of Quinpirole on Memory and Motor Performance in Monkeys. J. Neurosci. 1995, 15, 3429-3439.

(33) Smedes, F.; Kraak, J.; Poppe, H. Simple and Fast Solvent Extraction System for Selective and Quantitative Isolation of Adrenaline, Noradrenaline and Dopamine from Plasma and Urine. J. Chromatogr., Biomed. Appl. 1982, 231, 25-39.

(34) Andrew, R.; Watson, D.; Best, S.; Midgley, J.; Wenlong, H.; Petty, R. The Determination of Hydroxydopamines and other Trace Amines in the Urine of Parkinsonian Patients and Normal Controls. Neurochem. Res. 1993, 18, 1175-1177.

(35) Heinrichs, M.; Baumgartner, T.; Kirschbaum, C.; Ehlert, U. Social Support and Oxytocin Interact to Suppress Cortisol and Subjective Responses to Psychosocial Stress. Biol. Psychiatry 2003, 54, 1389-1398.

(36) Kema, I. P.; de Vries, E. G. E.; Muskiet, F. A. J. Clinical chemistry of serotonin and metabolites. J. Chromatogr., Biomed. Appl. 2000, 747, 33-48.
(37) Peeters, M. M.; van Grinsven, B.; Foster, C. W.; Cleij, T. J.; Banks, C. E. Introducing Thermal Wave Transport Analysis (TWTA): A Thermal Technique for Dopamine Detection by Screen-Printed Electrodes Functionalized with Molecularly Imprinted Polymer (MIP) Particles. Molecules 2016, 21, 552. 